\title{
BMJ Global Health Association of tobacco advertising, promotion and sponsorship (TAPS) exposure and cigarette use among Nigerian adolescents: implications for current practices, products and policies
}

\author{
Onyema G Chido-Amajuoyi, ${ }^{1}$ Dale S Mantey, ${ }^{1}$ Stephanie L Clendennen, ${ }^{2}$ \\ Adriana Pérez ${ }^{3}$
}

To cite: Chido-Amajuoyi $0 \mathrm{G}$, Mantey DS, Clendennen SL, et al. Association of tobacco advertising, promotion and sponsorship (TAPS) exposure and cigarette use among Nigerian adolescents: implications for current practices, products and policies. BMJ Glob Health 2017;2:e000357. doi:10.1136/ bmjgh-2017-000357

Received 30 March 2017 Revised 20 June 2017 Accepted 9 July 2017

\section{(a) CrossMark}

${ }^{1}$ Department of Epidemiology, Human Genetics and Environmental Sciences, The University of Texas Health Science Center at Houston, School of Public Health in Austin, Austin, Texas, USA ${ }^{2}$ Department of Health Promotion and Behavioral Sciences, The University of Texas Health Science Center at Houston, School of Public Health in Austin, Austin, Texas, USA ${ }^{3}$ Department of Biostatistics, The University of Texas Health Science Center at Houston, School of Public Health in Austin, Austin, Texas, USA

Correspondence to Dr Onyema G Chido-Amajuoyi; chido-a.o.greg@uth.tmc.edu

\section{ABSTRACT}

Background This study investigates the association between exposure to tobacco advertising, promotion and sponsorship (TAPS) and cigarette use behaviours among adolescents in five Nigerian regions. This is imperative given a 2015 WHO report on the global tobacco epidemic, revealing Nigeria has not met any of the MPOWER TAPS ban indicators instituted since 2008.

Methods Secondary data analysis of the 2008 Global Youth Tobacco Survey for Nigeria. Participants were 1399 adolescents, representative of 5 Nigerian regions. Weighted multivariable logistic regression models were used to assess the relationship between TAPS exposure and (1) past 30-day (current) cigarette use, (2) ever cigarette use and (3) susceptibility to use cigarettes among never cigarette users. Sensitivity analysis via complete case analysis and multiple imputation were conducted.

Results Ninety-five per cent of Nigerian adolescents reported exposure to TAPS. Among adolescents who had never smoked, $15 \%$ were susceptible to use cigarettes. Cumulative TAPS exposure was significantly associated with both an increased odds of current cigarette use (AOR: 1.73; 95\% Cl 1.09 to2.99) and ever cigarette use (AOR: $1.29 ; 95 \% \mathrm{Cl} 1.15$ to1.45); as well as increased susceptibility to cigarette smoking (AOR: $1.18 ; 95 \% \mathrm{Cl} 1.03$ to 1.34), among non-smokers.

Conclusion Given study results, the emergence of new tobacco products and novel platforms for TAPS globally, implementation of existing policies and enhancement of efforts to attain comprehensive bans on all forms of direct and indirect TAPS in line with article 13 of the WHO Framework Convention on Tobacco Control are needed to reduce TAPS exposure and curtail tobacco use in Nigeria.

\section{INTRODUCTION}

Strict implementation of regulatory policies on tobacco products in developed nations over the past decades ${ }^{1-3}$ have led the tobacco industry to concentrate survival efforts in low-income

\section{Key questions}

What is already known about this topic?

- Tobacco use is the leading cause of preventable morbidity and mortality, and its use is adopted mainly in the adolescent years.

- Tobacco control policies aimed at banning tobacco advertising, promotion and sponsorship (TAPS) are poorly enforced in most African nations, as such prevalence of exposure of adolescents to TAPS has been reported to be high in countries studied in this region.

- TAPS exposure is associated with tobacco product use in adolescents, as well as increased susceptibility to use tobacco products among nonsmoking adolescents.

\section{What are the new findings?}

- A vast majority of Nigerian adolescents (95.1\%) reported exposure to at least one form of TAPS.

- Exposure to TAPS is associated with cigarette use and susceptibility to use cigarettes in Nigerian adolescents.

- Cumulative exposure to multiple channels of TAPS is associated with cigarette use and susceptibility to use cigarettes in Nigerian adolescents.

\section{Recommendations for policy}

- This study demonstrates the need for advocacy for more active and frequent surveillance of adolescent tobacco use behaviours as recommended by the WHO Framework Convention on Tobacco Control (FCTC) article 20. The last multistate survey on adolescent tobacco use in Nigeria was conducted in 2008.

- Given associative findings between TAPS exposure and tobacco use, this study makes a strong case for effective implementation of regulations aimed at comprehensive bans on all forms of direct and indirect TAPS, in line with article 13 of WHO FCTC.

and middle-income countries (LMICs) with less governmental oversight and regulations. ${ }^{4}$ Rates of tobacco use in countries on the African 
Table 1 Nigeria WHO FCTC article 13 implementation status between 2008 and 2014 (MPOWER 2008, 2014)

\begin{tabular}{|c|c|c|c|}
\hline \multirow{2}{*}{$\begin{array}{l}\text { Year WHO FCTC } \\
\text { ratified }\end{array}$} & \multirow{2}{*}{$\begin{array}{l}\text { WHO FCTC article } 13 \text { (bans on tobacco } \\
\text { advertising promotion and sponsorship) }\end{array}$} & \multicolumn{2}{|c|}{ MPOWER Score } \\
\hline & & 2008 & 2014 \\
\hline \multirow[t]{2}{*}{2004} & Level of TAPS bans & No policy & $\begin{array}{l}\text { Complete absence of ban, or ban that does } \\
\text { not cover national television, radio and print } \\
\text { media }\end{array}$ \\
\hline & Compliance with bans & - & - \\
\hline
\end{tabular}

- Data not required/not applicable.

FCTC, Framework Convention on Tobacco Control; TAPS, tobacco advertising, promotion and sponsorship.

continent are not at epidemic levels; ${ }^{5}$ however, a substantial increase in the prevalence of tobacco product use has been projected. $^{6}$ African nations are vulnerable to the tobacco industry's efforts to recruit new smokers, given their rapidly growing adolescent population and governments unable or unwilling to implement appropriate tobacco control measures. ${ }^{4}$ The combination of increased tobacco industry marketing activities, limited government regulations and large adolescent populations ${ }^{4}$ puts vulnerable countries in Africa at risk of progression to an established tobacco use epidemic. ${ }^{6}$

The tobacco industry continues to devise new strategies to counter global tobacco control efforts, ${ }^{4}$ chief among these is an aggressive and deliberate youth-targeted marketing of tobacco products. ${ }^{8}$ Yearly, the tobacco industry invests tens of billions of dollars globally into swaying individuals to use its products, through tobacco advertising, promotion and sponsorship (TAPS). ${ }^{8}$ TAPS exposure has been shown to increase smoking initiation and sustained use among youth. ${ }^{9}{ }^{10}$ Poor regulation of tobacco industry activities in LMICs has created a conducive environment for TAPS and has led to a high prevalence of TAPS in this region. ${ }^{11}{ }^{12}$ Demonstrating the reach of these strategic marketing methods, Borzekowski et $a l^{13}$ found that $68 \%$ of 5-year old and 6-year-old children in LMICs could identify a cigarette brand logo. ${ }^{13}$

Nigeria, the most populous nation in Africa is at the forefront of this problem. With almost a third (31\%) of its population being youth, ages 10 years to 24 years, ${ }^{14}$ Nigeria boasts of one of the largest youth populations in the world. Evidence suggests cigarette smoking prevalence is on the rise in Nigeria. ${ }^{15} 16$ Furthermore, the activity of transnational tobacco companies (TTCs) in the country continues to grow, with TTCs such as British American Tobacco having established a physical presence in the country. Cigarette use prevalence among Nigerian adolescents, ages 13 years to 15 years, is $3.5 \%$, with $1.3 \%$ of cigarette users being females and $5.6 \%$ male. ${ }^{17} 18$

The Global Youth Tobacco Survey (GYTS) is a schoolbased survey designed to enhance the capacity of countries to monitor tobacco use among youth and to guide the implementation and evaluation of tobacco prevention and control programmes. ${ }^{19}$ The 2008 GYTS remains the most recent survey conducted for Nigeria.

The tobacco industry in Nigeria has historically interfered with the enactment and effective implementation of tobacco control policies. ${ }^{20}$ Nigeria signed the World Health Organization (WHO) Framework Convention on Tobacco Control (FCTC) on June 28, 2004, confirming its commitment to implement outlined tobacco control policies. $^{21}$ This framework-protocol approach legally binds member states to adopt measures aimed at reducing the supply and demand of tobacco products. ${ }^{21}$ WHO MPOWER was established in 2008 as a scale to measure country-level implementation of the WHO FCTC policies. ${ }^{22}$ Article 13 of WHO FCTC addresses measures aimed at preventing exposure to TAPS. ${ }^{21}$ Under this article, WHO has proposes member states adopt a complete ban on all forms of TAPS, having found it to be a more effective control tool than partial bans. ${ }^{8}$ This includes a recommendation for governments to strongly prohibit acts of corporate social responsibility (CSR) from the tobacco industry, ${ }^{8}$ which are usually initiatives that contribute to a county's economic or social development. ${ }^{23} \mathrm{CSR}$ has been shown to be a mechanism used by the tobacco industry to gain societal foothold in developing nations, ${ }^{47}$ thereby limiting governmental ability to strongly enforce regulatory sanctions. ${ }^{23}$

The letter ' $\mathrm{E}$ ' in MPOWER stands for 'Enforce bans on direct advertising, promotion and sponsorship of tobacco products', and it outlines 28 measures (excluding newly added measures for e-cigarettes) on which policy control of TAPS are measured. ${ }^{22}$ Measures in this category are grouped into (1) bans on direct TAPS which include national and international television, radio, billboard, internet, magazines or newspapers and (2) bans on tobacco promotion and sponsorship which include several categories of indirect TAPS. ${ }^{21}$

Comparing baseline scores of the MPOWER assessment in 2008 to 2014 (table 1) scores reported in the 2015 WHO report on the global tobacco epidemic, Nigeria still maintains a score of 'a complete absence of ban, or ban that does not cover national television, radio and print media'. ${ }^{17}$ Subnationally, of Nigeria's 36 states and Federal Capital Territory, only Cross River state currently has some form of ban on TAPS. ${ }^{17}$

Causal associations between tobacco use and a host of cardiovascular diseases, respiratory diseases and carcinoma has been strongly demonstrated, ${ }^{24}$ rendering lapses in tobacco control policy implementation highly perilous. With a WHO projected transition from communicable to non-communicable disease -led mortalities 
in developing countries, ${ }^{25}$ the importance of formative research on which preventive interventions can be based is crucial.

This study evaluates the association between TAPS exposure and (1) current cigarette use, (2) ever cigarette use and (3) susceptibility to use cigarettes among never cigarette using adolescents in Nigeria in 2008. Given that implementation of WHO FCTC article 13 has not changed significantly in Nigeria between 2008 and $2014,{ }^{17}$ we speculate the findings of this study may remain relevant to the present day, with regard to cigarette use behaviours in the country.

\section{METHODS}

\section{Study sample and population}

This is a secondary data analysis of the 2008 GYTS for Nigeria. The GYTS had a two-stage cluster sample and was designed to monitor tobacco use, attitudes and exposure to secondhand smoke among adolescents. The GYTS selected five cities in Nigeria: Abuja, Ibadan, Lagos, Kano and Cross River to represent the country's major geopolitical zones. The procedure is described in detail elsewhere. ${ }^{26}$

\section{Sampling design}

A complex sampling design was used to ensure adequate sample size. At the first sampling wave, school selection was proportional to the number of students enrolled in the selected classes; this sample wave was used to determine appropriate sample size for Nigerian adolescents in 2008. At the second sampling wave, schools were randomly selected for participation. A weighting factor was applied to each student record to adjust for non-response (by school, class and student) and probability of selection at the school and class levels. A final adjustment summed the weights by grade and sex to the population of school children in the selected grades in each sample site. Informed consent was obtained from respondents before data collection. The procedure is described in detail elsewhere. ${ }^{26}$

\section{Outcome measures}

\section{Ever cigarette use}

Respondents were considered ever users if they reported ever trying a cigarette, even one or two puffs, in their lifetime. Specifically, respondents were asked, 'Have you ever tried or experimented with cigarette smoking, even one or two puffs?' with those reporting 'yes' categorised as 'ever cigarette users'.

\section{Current cigarette use}

Respondents were considered current users if they reported use of cigarettes in the past 30 days, and those that had not were considered non-users. Specifically, respondents were asked, 'During the past 30 days, on how many days did you smoke cigarettes?' with those reporting one or more days categorised as "past 30 day cigarette users'.
Susceptibility to cigarette use

Among never users of cigarettes, susceptibility to use cigarettes was considered. This measure employed a two-item scale established by Pierce et al. ${ }^{27}$ Questions used to measure susceptibility were: 'If one of your best friends gives you a cigarette, would you smoke it?' and 'At any time during the next 12 months do you think you will smoke a cigarette?' Possible responses for these questions were 'definitely yes', 'probably yes', 'probably not' and 'definitely not'. If the given response for either question was anything other than 'definitely not', the respondent was categorised as susceptible to using cigarettes.

\section{Exposure to TAPS}

Several channels of TAPS exposure were assessed. First, product giveaways were assessed through the following question: 'has a cigarette representative ever offered you a free cigarette?' Second, logo branding was assessed through the following question: 'do you have something (t-shirt, pen, backpack, etc.) with a cigarette brand logo on it?' Possible responses for product giveaways and logo branding were 'yes' and 'no'. Those who stated, 'yes' were categorised as exposed to this channel of TAPS. Product giveaways and logo branding were combined to represent indirect TAPS exposure as outlined by WHO. ${ }^{8}$ Respondents who were exposed to one or both of these indirect industry marketing tactics were categorised as exposed.

Third, entertainment marketing was assessed through the question: 'during the past 30 days, when you watched sports events or other programs on TV, how often did you see cigarette brand names?' Fourth, product placement was assessed through the question: 'when watching TV, videos, or movies, how often do you see actors smoking?' For both entertainment marketing and product placement, responses ranged from 'never', 'sometimes/a few' and 'a lot'. Respondents who reported anything other than 'never' were categorised as being exposed to the respective channel of TAPS. Further, entertainment marketing and product placement were combined to represent $\mathrm{TV} /$ media exposure, with exposure to one or both channels considered as being exposed.

The fifth TAPS exposure was event sponsorship which was assessed by: 'when you go to sports events, tradeshows, concerts or community events, how often do you see advertisements for cigarettes?' Sixth, print media was assessed by: 'during the past 30 days, how many advertisements or promotions for cigarettes have you seen in newspapers or magazines?' Seventh was billboards exposure assessed by: 'during the past 30 days, how many advertisements for cigarettes have you seen on billboards?'. Possible responses for event sponsorship, print media and billboards exposure included 'never', 'sometimes/a few' and 'a lot'. Respondents who reported anything other than 'never' were categorised as being exposed to the respective channel of TAPS.

In addition to assessing the above individual exposure channels, a cumulative TAPS exposure variable was created by summing the number of TAPS channels to 
which each respondent was exposed. This ranged from zero (no exposure) to five (exposed to all five channelsindirect TAPS, TV/media, event sponsorship, print media and billboards).

\section{Covariates}

Sociodemographic factors and current non-cigarette tobacco use were included as covariates. Sex was dichotomised into male and female. Age was measured annually from 12 years to 17 years of age. Social influence of smoking was assessed via exposure to parental and peer smoking. Age and sex, ${ }^{28}$ as well as social influence, ${ }^{29}$ were used as covariates in all models as these variables have been found to be associated with cigarette use. Respondents who reported having either a parent or a friend who smoked were compared with those who neither had a parent nor a friend who smoked cigarettes.

Use of other tobacco products was also evaluated as a covariate. Participants who reported 'yes' to using smoked tobacco products other than cigarettes (eg, cigars, water pipes, cigarillos, little cigars, pipes) or smokeless tobacco (eg, chewing tobacco, snuff, dip) in the past 30 days were considered 'non-cigarette users'. Besides use of cigarettes being the primary outcome of interest in the index study, cigarettes remain the most advertised tobacco product in Nigeria, greatly benefiting from the enormous spending in TAPS and a historical tendency of the tobacco industry to undermine tobacco control in Nigeria. ${ }^{1520}$

\section{Statistical analysis}

Sampling weights were provided to represent the Nigerian adolescents in the five regions and to adjust for non-response and probability of selection. Weighted descriptive analyses are presented.

Because of missingness two sets of analyses were conducted: complete case analysis and multiple imputation (MI). A total of 544 of 23783 (2.28\%) data values were missing, this was across seven study variables: sex 8.9\% missing; current cigarette use $7.8 \%$; billboards exposure $5.2 \%$; age $5.0 \%$; ever cigarette use $4.9 \%$; event sponsorship exposure $3.5 \%$; and print media exposure $3.3 \%$. An assessment of the distribution of missing data across the data set revealed a non-monotone pattern of missingness. Under the assumption of missing values to be missing at random, MI was conducted using the package Multivariate Imputation by Chained Equations V.2.0 in R V.3.2.5. ${ }^{30}$ The set of predictors used to impute missing data for a given variable was selected from the data set based on their respective correlation with the target variable. Predictors with an absolute correlation of 0.2 or higher with a target variable were included in the set of predictors for that variable. MI was performed beginning with the variable with the least amount of missing data and ending with the variable with the most amount of missing data. Polytomous logistic regression was used to impute age, an ordered categorical variable. All other variables were binary, and logistic regression was used as the imputation method for each. Ten MIs were
Table 2 Characteristics of Nigerian adolescents (Global Youth Tobacco Survey, 2008)

Total sample $(n=1399 /$

$\mathrm{N}=29598$ )

\begin{tabular}{|c|c|}
\hline \multicolumn{2}{|l|}{ Sex } \\
\hline Female & $52.2 \%$ \\
\hline \multicolumn{2}{|l|}{ Age } \\
\hline Mean (SD) & $14.0(1.92)$ \\
\hline \multicolumn{2}{|l|}{ Channel-specific (TAPS) exposure } \\
\hline TV and movies & $88.1 \%$ \\
\hline Print media & $51.9 \%$ \\
\hline Billboards & $47.1 \%$ \\
\hline Sponsored events & $36.5 \%$ \\
\hline Indirect TAPS & $24.1 \%$ \\
\hline \multicolumn{2}{|l|}{ Cumulative TAPS exposure } \\
\hline No exposure & $4.9 \%$ \\
\hline One source & $24.7 \%$ \\
\hline Two sources & $21.4 \%$ \\
\hline Three sources & $23.1 \%$ \\
\hline Four sources & $20.3 \%$ \\
\hline Five sources & $5.6 \%$ \\
\hline \multicolumn{2}{|l|}{ Tobacco use } \\
\hline Ever cigarette users & $14.7 \%$ \\
\hline Current cigarette users & $4.2 \%$ \\
\hline Susceptible to cigarettes & $15.1 \%$ \\
\hline Past 30-day other tobacco users & $19.0 \%$ \\
\hline Social influence (yes) & $21.1 \%$ \\
\hline
\end{tabular}

TAPS, tobacco advertising, promotion and sponsorship.

generated using this methodology via Gibbs sampling. Then, the models stated below were fit on each one of the 10 imputed data sets. Those 10 models were pooled to obtain the final estimates from MI. ${ }^{31}$

Fifteen multivariable logistic regression models assessed the relationship between each TAPS exposure category (five in total) and each outcome variable (three in total). Further, other three multivariable logistic regression models assessed the relationship between cumulative TAPS exposure and each of the three outcomes. All analyses were conducted using STATA V.14.0 (College Station, Texas, USA).

\section{RESULTS}

Table 2 provides descriptive statistics. Tables 3 and 4 have results for both complete case and MI analyses; from this point forward we will only refer to MI findings, because it is similar to complete cases.

\section{Descriptive statistics}

The sample was $52.2 \%$ male with a mean age of 14.0 (SD: 1.92). Overall, $14.7 \%$ reported ever smoking a cigarette, and $4.2 \%$ reported current cigarette use. While $82.0 \%$ of 


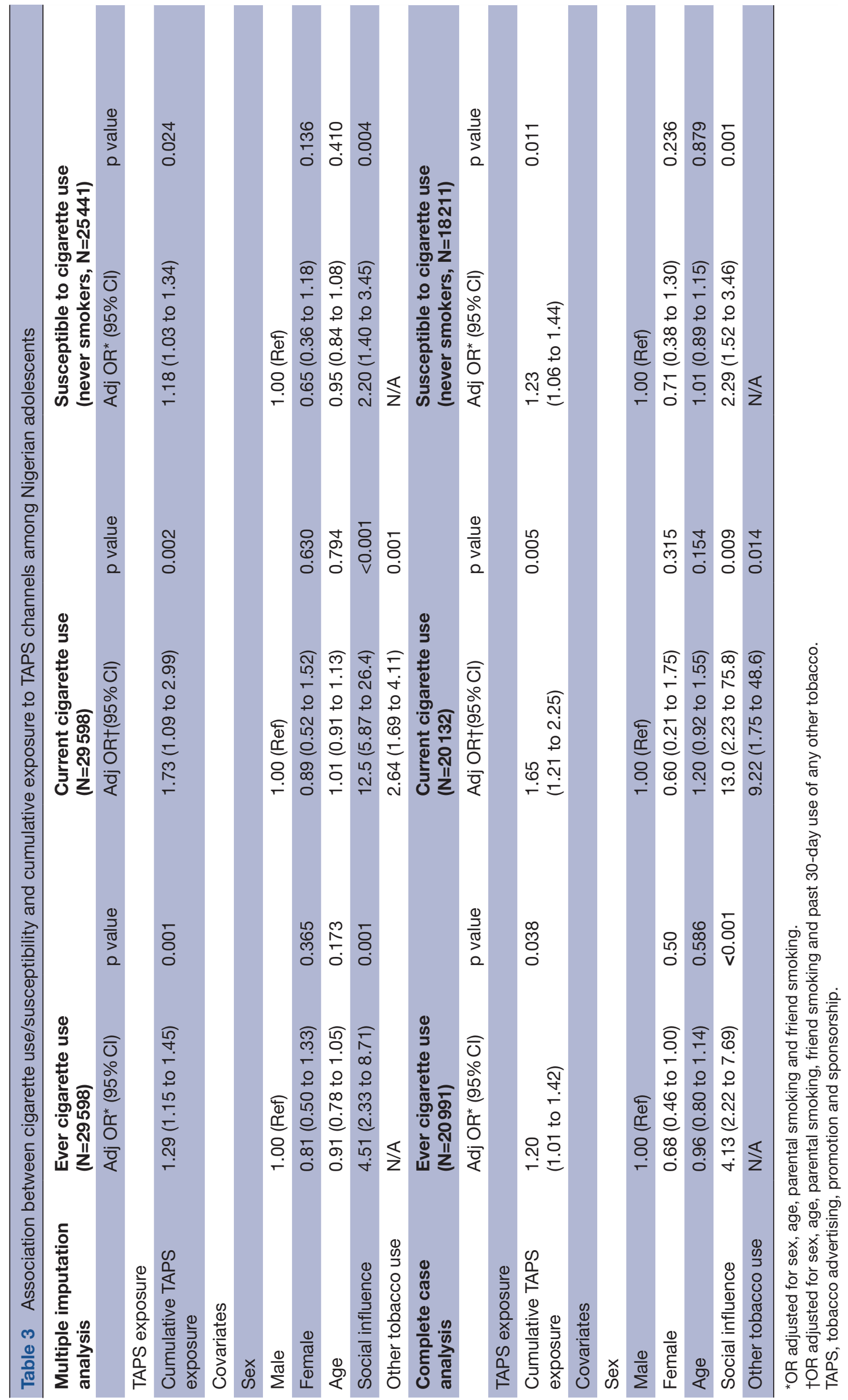

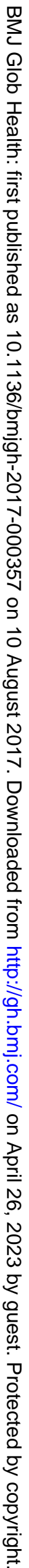


Table 4 Association between cigarette use/susceptibility and exposure to individual TAPS channels among Nigerian adolescents

${ }^{*}$ OR adjusted for sex, age, parental smoking and friend smoking.

†OR adjusted for sex, age, parental smoking, friend smoking and past 30-day use of any other tobacco.

TAPS, tobacco advertising, promotion and sponsorship.

the sample reported no tobacco use in the past 30 days, $15.1 \%$ of this proportion was found to be susceptible to cigarette smoking. As seen in table 2, the vast majority of the sample $(95.1 \%)$ reported exposure to at least one source of TAPS.

\section{Ever cigarette use}

One additional exposure to another channel of TAPS increased the MI odds of ever use of cigarettes by 1.29 (95\% CI 1.15 to 1.45 ) after adjusting for sex, age and social influence (table 3 ).

When exploring each individual channel, exposure to indirect TAPS was associated with ever use of cigarettes (AOR: 3.75; 95\% CI 2.65 to 5.30) after adjusting for sex, age and social influence (table 4). Similar results were observed with complete case analysis.

\section{Current cigarette use}

With one additional exposure to another TAPS channel, students' odds of current cigarette use increased by 1.73 (95\% CI 1.09 to 2.99) when adjusting for sex, age, social influence and past 30-day non-cigarette tobacco use (table 3). Furthermore, event sponsorship (AOR: 2.44; $95 \%$ CI 1.24 to 4.81 ) was associated with current cigarette use when adjusting for sex, age, social influence and past 30-day non-cigarette tobacco use (table 4).

\section{Susceptibility to cigarette use}

Cumulative TAPS exposure was associated with increased susceptibility to use cigarettes among never users. With one additional exposure to another TAPS channel, the odds of susceptibility to cigarette use increased by 1.18 (95\% CI 1.03 to 1.34 ) when adjusting for sex, age and social influence (table 3). Further, event marketing (AOR: $1.61 ; 95 \%$ CI 1.11 to 2.35 ) was statistically associated with increased cigarette use susceptibility among never users when adjusting for sex, age and social influence (table 4).

\section{DISCUSSION}

This study reveals a high prevalence of TAPS exposure among adolescents in Nigeria, a country with complete absence of ban, or a ban that does not cover national television, radio and print media. ${ }^{172}$ This finding is consistent with studies that have found regional prevalence of adolescent exposure to TAPS to correspond directly to the level of enforcement of TAPS ban in the country. ${ }^{12}$

Cumulative exposure to multiple channels of TAPS was associated with both cigarette use and susceptibility to use cigarettes among Nigerian adolescents. These findings mirror similar associations found in USA, between adolescent TAPS exposure and use of cigarettes, as well as susceptibility to use cigarettes. ${ }^{24} 3233$ Evidence from longitudinal studies demonstrating this association in other parts of the world are well documented, ${ }^{24}$ however, similar longitudinal studies have yet to be conducted in Nigeria. This cross-sectional study, to the best of our 
knowledge, is the first to establish an association between TAPS exposure and cigarette use among adolescents in Nigeria.

Exposure to indirect TAPS (free product giveaways and logo branding) was associated with ever use of cigarettes, while exposure to tobacco industry-sponsored events was associated with current cigarette use and increased susceptibility to use cigarettes. Despite indirect TAPS having the lowest reported exposure prevalence, it had the strongest association with ever use of cigarettes among Nigerian adolescents, compared with other channels of exposure. This finding may suggest a high potency of indirect TAPS in initiating cigarette use among adolescents. This may also imply that direct receipt of tobacco products or promotional gift items may be more impactful than when exposed via other media. The high odds of ever use of cigarettes following exposure to indirect TAPS may be attributed to the capacity of indirect TAPS to circumvent bans, ${ }^{34}$ as well as its independence of socioeconomic status for exposure. For example, individuals who are of low socioeconomic status with limited access to media tools may be conferred protection against exposure to several forms of TAPS such as television-based or print media-based TAPS ${ }^{35}$ however, this is not applicable to indirect TAPS.

Exposure to sponsored events was found to be associated with increased susceptibility to use cigarettes, as well as being a current user of cigarettes. The Nigerian music and entertainment industry has been one of the more successful sectors demonstrating Nigeria's potential for growth in recent years. ${ }^{36}$ Keen to take advantage of this largely popular industry, increased promotional investment of the tobacco industry in this sector may explain our finding. ${ }^{37}$ Tobacco industry-sponsored musical concerts and events in Nigeria have been made free of charge or drastically subsidised, ${ }^{37}$ ensuring individuals of all socioeconomic strata can attend and are thereby exposed to tobacco product promotions.

Several studies have found that countries with comprehensive TAPS bans have lower rates of adolescent tobacco use and initiation to tobacco use than countries with incomplete or non-existent TAPS bans. ${ }^{17} 38$ This relationship between level of TAPS restrictions and adolescent tobacco use demonstrates the effect of robust governmental implementation of article 13 of the WHO FCTC. Our study supports this assertion, by demonstrating a positive relationship between TAPS exposure and susceptibility of adolescents to cigarette use initiation, in an environment with poor TAPS regulation. ${ }^{17}$

Amid the absence of progress in Nigeria's implementation of comprehensive bans in line with the WHO FCTC article 13 recommendations since first MPOWER assessment in 2008; tobacco marketing methods, as well as tobacco products, are evolving globally. For example, electronic cigarettes have emerged the most widely used tobacco product in the USA, ${ }^{39}$ while youth exposure to tobacco product advertising on the internet has been shown to rank highly compared with other exposure channels in the $\mathrm{USA}^{40}$ and to be of rising prevalence in Australia. ${ }^{41}$ These have been shown to strongly influence tobacco use behaviours in adolescents in these regions, with internet-based TAPS shown to be associated with traditional and electronic cigarette use, ${ }^{40} 4243$ while research also shows electronic cigarettes can be a gateway to conventional tobacco product use. $^{44}{ }^{45}$ The prevalence of these novel products (eg, hookah and e-cigarettes) and TAPS exposure channels (eg, internet), as well as their relationship to tobacco use behaviours among Nigerian adolescents remains relatively unknown, greatly highlighting the need for further studies.

Given the known health consequences of tobacco product use $\mathrm{e}^{24}$ and a projected epidemiological transition of most developing nations from infectious disease-led to chronic disease-led mortality rates, ${ }^{46}$ it is imperative Nigeria adopts strategies aimed at developing a preventive capacity against tobacco use-related chronic diseases. This is essential given a lack of basic monitoring facilities for surveillance of tobacco use or its sequelae; notably, as of 2014, Nigeria was reported to have no national, population-based cancer registry. ${ }^{25}$ WHO FCTC remains a key evidence-based policy level intervention with the potential to ensure signee member countries attain optimal tobacco control. $^{21}$

This study was subject to several limitations. First, given the date of collection of data used for our analysis, findings may not be entirely reflective of the present day, however a parallel absence of implementation of antiTAPS control policies within this time frame, may have ensured that findings still remain relevant. More so, this represents the only available multistate survey data providing insight on cigarette use in this age group in Nigeria and informs their current WHO reported cigarette use prevalence. ${ }^{17}$ This greatly demonstrates a poor compliance of the Nigerian government with article 20 of WHO FCTC, which encourages active surveillance of tobacco use and greatly demonstrates the need for more frequent surveillance in the country. Second, data were obtained from a cross-sectional survey, and carry a central limitation of inability to claim a causal link between TAPS exposure and cigarette use behaviours among the sample. Additional limitation includes the possibility for recall bias as all data were self-reported.

Being the first to examine the association of TAPS exposure and cigarette use behaviours among Nigerian adolescents, this study offers baseline insight on which future investigations can be built. More so, our findings have implications for public health regulations and intervention programmes, given the causal link found between TAPS exposure and adolescent tobacco use in other parts of the world. ${ }^{24}$ Furthermore, the study survey (GYTS 2008) coincides with the year of baseline institution of the WHO MPOWER package ${ }^{22}$ globally, hence it provides insight to the state of the association between TAPS exposure and cigarette use behaviours before this implementation measurement tool was instituted. This 
can be crucial as a baseline point of analysis for future policy impact evaluation studies.

\section{CONCLUSION}

This study brings to light the poor adherence of the Nigerian government to article 20 of WHO FCTC, which encourages active surveillance of tobacco use, given the absence of more recent data on adolescent tobacco use in the country. The need for frequent and more recent surveys of adolescent tobacco use is highlighted, as well as the need for further studies in this region, given the emergence of new tobacco products and TAPS media since the survey for this study was conducted.

Also, exposure to TAPS is associated with cigarette use, as well as increased susceptibility to use cigarettes among non-smoking Nigerian adolescents. Given an absence of implementation of regulations enforcing bans on TAPS in Nigeria in line with article 13 of WHO FCTC, we speculate findings from this study may still be relevant to the present day. Effective governmental implementation of existing control policies and ensuring attainment of comprehensive bans on all forms of direct and indirect TAPS may be crucial to curb tobacco use among adolescents in Nigeria.

Acknowledgements The authors thank WHO and the US Centres for Disease Control and Prevention (CDC) for making data used in this study available. The authors also thank WHO MPOWER 2008 and 2014 for adaptations on table 1.

Contributors OGC-A conceptualised the research and was involved in all aspects of analysis, interpretation and manuscript preparation. DSM was involved in all aspects of statistical analysis, as well as revisions of the manuscript. SLC conducted multiple imputation analysis, and revisions of the manuscript. AP supervised the overall project, revised statistical methods and manuscript content.

Competing interests None declared.

Ethics approval Federal Ministry of Health, Nigeria.

Provenance and peer review Not commissioned; externally peer reviewed.

Data sharing statement № additional data are available.

Open Access This is an Open Access article distributed in accordance with the Creative Commons Attribution Non Commercial (CC BY-NC 4.0) license, which permits others to distribute, remix, adapt, build upon this work non-commercially, and license their derivative works on different terms, provided the original work is properly cited and the use is non-commercial. See: http://creativecommons.org/ licenses/by-nc/4.0/

(C) Article author(s) (or their employer(s) unless otherwise stated in the text of the article) 2017. All rights reserved. No commercial use is permitted unless otherwise expressly granted.

\section{REFERENCES}

1. Jamison N, Tynan M, MacNeil A, et al. Federal and state cigarette excise taxes - United States, 1995-2009. MMWR Morb Mortal Wkly Rep 2009;58:524-7.

2. Gostin LO. FDA regulation of tobacco: politics, law, and the public's health. JAMA 2009;302:1459-60.

3. Chaloupka FJ, Yurekli A, Fong GT. Tobacco Taxes as a tobacco control strategy. Tob Control 2012;21:172-80.

4. Gilmore AB, Fooks G, Drope J, et al. Exposing and addressing tobacco industry conduct in low-income and middle-income countries. Lancet 2015;385:1029-43.

5. Thun M, Peto R, Boreham J, et al. Stages of the cigarette epidemic on entering its second century. Tob Control 2012;21:96-101.
6. Méndez D, Alshanqeety $\mathrm{O}$, Warner KE. The potential impact of smoking control policies on future global smoking trends. Tob Control 2013;22:46-51.

7. McDaniel PA, Cadman B, Malone RE. African media coverage of tobacco industry corporate social responsibility initiatives. Glob Public Health 2016:1-15.

8. World Health Organization. Enforcing bans on tobacco advertising, promotion and sponsorship: who Report on the global tobacco epidemic. Geneva: World Health Organization, 2013. http://apps. who.int/iris/bitstream/10665/85380/1/9789241505871_eng.pdf (accessed 29 Mar 2017).

9. Everett SA, Warren CW, Sharp D, et al. Initiation of cigarette smoking and subsequent smoking behavior among U.S. high school students. Prev Med 1999;29:327-33.

10. Madkour AS, Ledford EC, Andersen L, et al. Tobacco advertising/ promotions and adolescents' smoking risk in Northern Africa. Tob Control 2014;23:244-52

11. Agaku IT, Adisa AO, Akinyamoju AO, et al. A cross-country comparison of the prevalence of exposure to tobacco advertisements among adolescents aged 13-15 years in 20 low and middle income countries. Tob Induc Dis 2013;11:1.

12. English LM, Hsia J, Malarcher A. Tobacco advertising, promotion, and sponsorship (TAPS) exposure, anti-TAPS policies, and students' smoking behavior in Botswana and South Africa. Prev Med 2016;91S:S28-34.

13. Borzekowski DL, Cohen JE. International reach of tobacco marketing among young children. Pediatrics 2013;132:e825-31.

14. Population Reference Bureau. The World's Youth: 2013 Data Sheet, 2013. http://www.prb.org/pdf13/youth-data-sheet-2013.pdf (accessed 29 Mar 2017).

15. Nwhator SO. Nigeria's costly complacency and the global tobacco epidemic. J Public Health Policy 2012;33:16-33.

16. Mbulo L, Ogbonna N, Olarewaju I, et al. Preventing tobacco epidemic in LMICs with low tobacco use - Using Nigeria GATS to review WHO MPOWER tobacco indicators and prevention strategies. Prev Med 2016;91S:S9-15.

17. World Health Organization. WHO report on the global tobacco epidemic, 2015: raising Taxes on tobacco, 2015. http://apps.who.int/ iris/bitstream/10665/178574/1/9789240694606_eng.pdf (accessed 29 Mar 2017).

18. Ekanem I, Asuzu M, Anunobi C, et al. Prevalence of tobacco use among youths in five centres in Nigeria: a global youth tobacco survey (GYTS) approach. JCMPH 2010;22:1-67.

19. Global Tobacco Surveillance System Collaborating Group. Global tobacco Surveillance System (GTSS): purpose, production, and potential. J Sch Health 2005;75:15.

20. Egbe CO, Bialous SA, Glantz SA. Avoiding "A Massive Spin-Off Effect in West Africa and Beyond": The Tobacco Industry Stymies Tobacco Control in Nigeria. Nicotine Tob Res 2017;19:877-87.

21. World Health Organization. WHO Framework Convention on tobacco control, 2003. http://apps.who.int/iris/bitstream/10665/42811/1/ 9241591013.pdf (accessed 29 Mar 2017).

22. World Health Organization. WHO report on the global tobacco epidemic. 2008: the MPOWER package 2008 http://apps.who.int/ iris/bitstream/10665/43818/1/9789241596282_eng.pdf (accessed 29 Mar 2017).

23. Jakpor P. Nigeria: how British American Tobacco undermines the WHO FCTC through agricultural initiatives: invited commentary. Tob Control 2012;21:220.

24. US Department of Health and Human Services. The health consequences of smoking -50 years of progress. A report of the Surgeon General, 2014. https://www.surgeongeneral.gov/library/ reports/50-years-of-progress/full-report.pdf (accessed 29 Mar 2017).

25. World Health Organization (WHO). World Health Organization -Noncommunicable Diseases (NCD) Country Profiles-Nigeria. 2014 http://apps.who.int/iris/bitstream/10665/128038/1/9789241507509_ eng.pdf (accessed 29 Mar 2017).

26. Warren CW, Jones NR, Peruga A, et al. Global youth tobacco surveillance, 2000-2007. MMWR Surveill Summ 2008;57:1-28.

27. Pierce JP, Farkas AJ, Evans N, et al. An improved surveillance measure for adolescent smoking? Tob Control 1995:S47-56.

28. Richardson A, Williams V, Rath J, et al. The next generation of users: prevalence and longitudinal patterns of tobacco use among US young adults. Am J Public Health 2014;104:1429-36.

29. Sutfin EL, Sparks A, Pockey JR, et al. First tobacco product tried: associations with smoking status and demographics among college students. Addict Behav 2015;51:152-7.

30. Buuren S, Groothuis-Oudshoorn K. mice: Multivariate Imputation by Chained Equations in R. J Stat Softw 2011;45:1-67.

31. Rubin DB. Multiple imputation after $18+$ years. J Am Stat Assoc 1996;91:473-89. 
32. Altman DG, Levine DW, Coeytaux R, et al. Tobacco promotion and susceptibility to tobacco use among adolescents aged 12 through 17 years in a nationally representative sample. Am J Public Health 1996;86:1590-3.

33. Pierce JP, Choi WS, Gilpin EA, et al. Tobacco industry promotion of cigarettes and adolescent smoking. JAMA 1998;279:511-5.

34. Assunta M, Chapman S. The tobacco industry's accounts of refining indirect tobacco advertising in Malaysia. Tob Control 2004;13(suppl 2):ii63-70.

35. Tafawa AO, Viswanath $\mathrm{K}$, Kawachi I, et al. Mass media exposure, social stratification, and tobacco consumption among Nigerian adults. Cancer Causes Control 2012;23:45-55.

36. Letts R. The effects of globalisation on music in five contrasting countries: Australia, Germany, Nigeria, the Philippines and Uruguay. ParisInternational Music Council/Sydney: Music Council of Australia, 2003. http://imc-cim.org/mmap/pdf/int-dl-finrep.pdf (accessed 29 Mar 2017).

37. Patel P, Okechukwu CA, Collin J, et al. Bringing 'Light, Life and Happiness': British American Tobacco and musicsponsorship in sub-Saharan Africa. Third World Q 2009;30:685-700.

38. Saffer H, Chaloupka $F$. The effect of tobacco advertising bans on tobacco consumption. J Health Econ 2000;19:1117-37.

39. Singh T, Arrazola RA, Corey CG, et al. Tobacco use among Middle and High School students--United States, 2011-2015. MMWR Morb Mortal Wkly Rep 2016;65:361-7.
40. Singh T, Agaku IT, Arrazola RA, et al. Exposure to advertisements and electronic cigarette use among US Middle and High School students. Pediatrics 2016;137:e20154155.

41. Dunlop S, Freeman B, Perez D. Exposure to Internet-Based tobacco advertising and branding: results from Population surveys of Australian Youth 2010-2013. J Med Internet Res 2016;18:e104.

42. Fulmer EB, Neilands TB, Dube SR, et al. Protobacco Media exposure and Youth susceptibility to Smoking Cigarettes, Cigarette Experimentation, and current tobacco use among US Youth. PLOS One 2015;10:e0134734.

43. Mantey DS, Cooper MR, Clendennen SL, et al. E-Cigarette Marketing exposure is Associated with E-Cigarette Use among US Youth. J Adolesc Health 2016;58:686-90.

44. Barrington-Trimis JL, Berhane $\mathrm{K}$, Unger JB, et al. The E-cigarette Social Environment, E-cigarette Use, and susceptibility to Cigarette Smoking. J Adolesc Health 2016;59:75-80.

45. Wills TA, Knight R, Sargent JD, et al. Longitudinal study of e-cigarette use and onset of cigarette smoking among high school students in Hawaii. Tob Control 2017;26:34-9.

46. World Health Organization (WHO). Global Health Observatory Data Repository, Age-standardized death rate by three Major cause groups, both sexes. Data by country. 2012 http://www.who.int/gho/ mortality_burden_disease/en/ (accessed 29 Mar 2017). 